\title{
THE INFLUENCE OF NATIONAL CULTURE ON AMERICAN BUSINESS PEOPLE - MANAGERIAL IMPLICATIONS FOR CENTRAL EUROPE
}

\author{
Cook, G.
}

This text presents some of the fundamental values and traits of American national culture with a focus on their potential effect on the behavior of US business people. The goal of the article is to map potential differences from the habits and norms typical in the Central European region (CEE region), i.e. to identify those which might have an important impact on business activities. Methodologically, the text includes a brief literary review including various different cultural frameworks; the paper then utilizes primarily descriptive and comparative methods, as well as analysis and synthesis, to comprehend the issue in hand. The author complements this input with real-life personal and professional experience gained by working and living in both geographic regions. Finally, the article provides some key managerial implications for executives operating within the CEE environment who potentially conduct business transactions with Americans or US-based organizations.

JEL Classification: M12, M14

\section{Introduction}

Regardless of the fact that cultural differences can have a tremendous impact on international business activities - as illustrated by many authors and business practices - many business people continue to underestimate, or even ignore, their potential effect; thus, in many cases, they act in a way which diminishes the effectiveness of their efforts. There is a vast amount of literature dealing with cultural issues, either on a theoretical level or texts dealing with real life business experience; nevertheless, there is still an opportunity to add works with a specific combination of both. This approach could provide comprehensive knowledge of the issue and help enhance the knowledge and behavior of managers.

As culture is time and place specific, business and organizational culture itself is influenced by the general values embodied in a culture. Thus, unlike many business oriented texts which focus directly on specific business culture, the main goal of this article is to present some key aspects and values of American culture and elucidate their potential impact on the behavior of American business people during international business transactions. This knowledge is applied to interactions within the Central European business environment, both to illustrate the impact of cultural differences in business and to make it more practical for readers. In order to get to the core issue at hand, the author also complements this input with real-life personal and professional experience gained by working and living in both geographic regions. Some managerial implications for executives working within Central European countries are the final and logical conclusion to the article.

\section{Methods}

From a methodological perspective, this article utilizes primarily descriptive and comparative methods as well as an analysis and synthesis. In addition, it is based on a review of various literary works related to the field as well as the author's own extensive personal and professional experience living and working in both environments. Insight from American expatriates living and working in the Central European environment was also included.

\section{Key Aspects, Values \& Dimensions of American Culture}

Effective communication, interactions, and understanding are crucial for successful business; however, even when there is little or no language barrier, cultural differences can still present obstacles. Why do Americans talk and act in the particular way they do? What are their underlying thoughts and opinions? What motivates them? This text looks at some key aspects and values present in American culture; it does 
so from a variety of perspectives in an attempt to provide the reader with a well-rounded view. As a first example, the framework of key American values and assumptions - as identified by authors Althen, Doran \& Szmania - is specified in the table below.

Table 1 American Values and Assumptions

\begin{tabular}{|c|c|c|}
\hline Individualism & Freedom & Competitiveness \\
\hline Privacy & Equality & Informality \\
\hline $\begin{array}{c}\text { The Future, } \\
\text { Change \& Progress }\end{array}$ & $\begin{array}{c}\text { Goodness of } \\
\text { Humanity }\end{array}$ & Time \\
\hline Achievement & Action & Hard Work \\
\hline Materialism & Directness & Assertiveness \\
\hline
\end{tabular}

Source: Author's creation based on data from G. Althen, A. Doran \& S. Szmania, American Ways: A Guide for Foreig-ners in the United States, $2^{\text {nd }} \mathrm{ed}$. Intercultural Press, Boston 2003.

One particularly strong aspect of American values is that of equality; for example, it does not matter who you or your parents are - there is a fundamental belief that nobody is born superior to anybody else. "What is distinctive about the American outlook on the matter of equality are the underlying assumptions that (1) no matter what a person's initial station in life, he or she has the opportunity to achieve high standing and (2) everyone, no matter how unfortunate, deserves some basic level of respectful treatment. ...Their notions of equality lead Americans to be quite informal in their general behavior and in their relationships with other people” (Althen, Doran and Szmania, 2003, p. 15-16). Americans generally dislike it when somebody treats them with too much deference; likewise, it is seen as socially unacceptable to insist on it from someone else. This is illustrated, for example, in the lack of use of titles; it is rare to use them and insisting upon it is often seen as elitist. Americans are well-known for using first names on many occasions, e.g. where it would be inappropriate outside the USA. However, in the USA, informality - in speech, manners or dress - does not imply a lack of respect.

Americans tend to have a positive view of change; they also often see themselves as masters of their own fate; in other words, they believe they have the ability to affect their own future. Oftentimes, Americans will be impatient with situations where people seem to be passively accepting of less than ideal circumstances; it is difficult for them to understand why something isn't done about it. In situations like these, they tend to want to take action; initiative is generally highly revered. Overall, Americans tend to look forward to the future rather than backward into history.

Closely connected with this positive view of and ability to affect change, as well as the value of equality, is a fundamental belief that humanity is good and the possibility to improve exists. The typical American phrase 'When there's a will, there's a way.' illustrates this concept. There is an extensive culture surrounding self-improvement, selfhelp, and how-to knowledge. Many people in the USA tend to be 'do-it-yourself' individuals. Volunteering for worthy causes is considered admirable.

Time is often seen as a scarce commodity; it is spent wisely or wasted. Americans are schedule oriented; punctuality is critical in both the private and professional spheres. Americans work hard to save time, and life in the United States often involves extensive use of time saving devices. Efficiency is also highly prized and this can be seen in the practical and results-oriented manner in which business and personal transactions are conducted. For example, Americans will often resent the 'official niceties' at the beginning of an international business meeting if they are seen as too excessive; rather, an American may perceive them as unnecessary and possibly insincere. International personnel may miss the ritual socializing - such as chatting over coffee and 'chlebicky' - customary in their home nations. Americans can be impatient though with what they perceive as 'wasting' time beyond a certain courtesy level. In addition, in the office environment, personal visiting is often saved for off-hours.

In terms of interactions, Americans tend "to be frank, open and direct in their dealings with other people. ... [There is an American] idea that people should explicitly state what they think and what they want from other people. Americans usually assume that conflicts or disagreements are best settled by means of forthright discussions among the people involved. ...Americans will often speak openly and directly to others about things they dislike, particularly in a work situation" (Althen, Doran and Szmania, 2003, p. 27-28). 'Constructive' feedback or communication is admired, i.e. saying something in a way that avoids offending but also communicates an 'issue' (i.e. problem) and how something can be improved or resolved. "In many countries, people will tell you what they think you want to hear, whether or not it is true. To them, this is the polite thing to do. To Americans, it is considered misleading - even dishonest - to distort the facts on purpose, however kind the motive. In the United States, directness tends to have a higher priority than politeness. We are taught from childhood that 'honesty is the best policy'....With us, trust and truth are interrelated and very important” (Lanier and Davis, 2005, p. 17). Americans will discuss a wide variety of subjects in an open manner; there are, however, certain topics that are generally not discussed in public - e.g. politics, religion, and money (i.e. personal finances, particularly one's salary). Many Americans often find silence awkward and will try to fill it with small talk. 
Closely related to Americans' sense of individuality is the high priority placed on privacy and the sense of public and privates selves. From a historical perspective, Americans have inherited a sense of openness. This makes it relatively easy for them to strike up new acquaintances and proceed directly to the point at hand in business negotiations. In many cases, it can be seen in the informal approach to interpersonal interactions - visiting friends without calling first or stopping by the boss's office without an appointment. It can be seen in the open layout of houses, yards and the cubical communities common in many US organizations. However, there is a concurrent, and sometimes confusing for international visitors, importance placed on privacy. The approach used in the same houses, gardens and outdoor fences delineating what is 'mine' and 'yours' and what is 'private' versus 'public' often contrasts with the common approach to public assets in some other nations. Within the professional sphere, for example, there is a strong preference for major business negotiations to be carried out in private rather than amid an environment of noisy chaos. In particular, anything related to personnel evaluations is seen as extremely confidential information and should only be discussed in private. A manager giving constructive or critical feedback to an employee would most likely not do this in front of anyone else. In terms of socializing with co-workers outside the office, the approach and attitude varies widely by organization and industry. However, from a personal perspective, privacy is also cherished and wanting 'some time alone' is seen as natural and healthy. It is common for children to have their own rooms from a young age; families live in small groups rather than in multigenerational units. Privacy and alone time is seen as a space to rejuvenate from the busy chaos and pressures of life typical in America.

In terms of communications, this sense of privacy extends to a distinct sense of personal space; when talking, typical Americans are most comfortable if the other person is at least 50 centimeters away. Americans also try to keep their bodies apart in crowded situations, e.g. on an elevator. From some cultural perspectives, Americans may seem 'touchy' and from others rather cold; it is common for us to offer a hug to a friend in farewell, poke each other in the ribs, or offer an arm around the shoulder in sympathy. From the author's experience living and working in the Central European region, Americans tend to be more private with their public display of affection than the norms in CEE. In the professional realm, the most common greeting is a brief but firm handshake; looking the person in the eye and smiling is also appropriate. Americans do not typically share other physical greetings or touch each other in the work environment, e.g. kiss on the cheek.
Another perspective on dominant American values is provided by authors Lanier and Davis; details are shown in the following table. There is some overlap between the two frameworks as can also be seen by some examples provided later within the third framework derived by intercultural research guru, Professor Geert Hofstede.

\section{Table 2 Dominant US American Values}

\begin{tabular}{|c|c|}
\hline Egalitarianism & Directness \\
\hline Silence & Public and Private Selves \\
\hline Social Distance and Touching & Americans in Motion \\
\hline Controlling Nature & $\begin{array}{c}\text { Personal Progress and } \\
\text { Changing Jobs }\end{array}$ \\
\hline Materialism & Parochialism \\
\hline
\end{tabular}

Source: Author's creation based on data from A. Lanier and J. Davis, Living in the USA, 6 $6^{\text {th }}$ ed. Intercultural Press, Boston 2005.

Americans tend to be an active, restless people often on the go. This can be seen in the busy routines of their daily lives, both personally and professionally. Multitasking is common both in the professional and personal spheres. Furthermore, Americans tend to be quite mobile. This can be seen in the labor market, where it is common and completely acceptable to change jobs every couple of years to facilitate professional development; the norms for how often one typically changes a job vary by industry. In many cases, this change in professional position also involves a change in city or state, even when continuing to work within the same organization. Furthermore, many organizations advise and occasionally even require employees to rotate to different geographical locations within the company throughout the professional development process. In terms of physical movement, while the percentage of Americans who have a passport is lower in comparison to many countries, it is quite common to travel extensively within the USA. Furthermore, it is commonplace for children to move out of their parent's house at 18 or when they go to university and to live independently from that point onwards. Having a family with siblings spread all over the country is not unusual. As implied above, it is typical for families to move from city to city or even state to state. "Our ability to move across the country, where we have no friends and family, may seem baffling to many visitors... Moving is extremely common, as is the freedom people have to reinvent their identities when they do so. People change their names, their religions and very often attempt to change their economic status along the way" (Lanier and Davis, 2005, p. 22).

Ironically, while Americans tend to be quite mobile, a certain parochialism also co-exists in many cases. The 
Figure 1 Hofstede's Cultural Dimensions - USA \& Czech Republic

Source: Geert Hofstede, available online at: http://geert-hofstede.com/ united-states.html

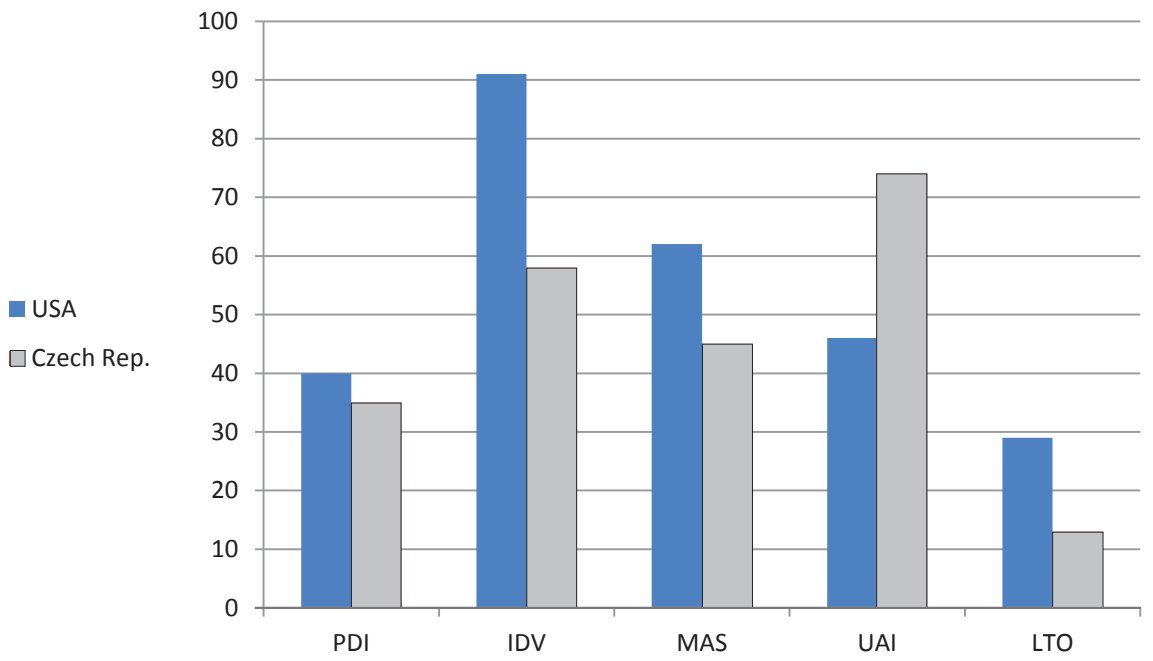

United States is a geographically enormous country and this contributes to the fact that many Americans think there is enough there to keep them busy without getting too involved internationally. This fact is reflected in much of the US-centric news media, relatively low awareness of some Americans regarding global affairs, and the unfortunate stereotype of Americans being monolingual. Of course, this provincial outlook coincides again with globalization and its effect on the USA and Americans. Many US citizens are well-informed individuals with a broad international perspective.

The graph below provides the scores of the United States on the cultural dimensions as identified and developed by Professor Geert Hofstede; originally four dimensions were specified and LTO was added later. Work has continued in this field and a recently added dimension will be discussed later in this article. For comparative purposes, the same data is provided for the Czech Republic.

Power Distance (PDI) refers to what extent hierarchical and power differences exist and are accepted in a particular nation; high PDI scores indicate significant differences are found as well as an acceptance of this situation. With regard to PDI, the USA has a score of 40 , "which underscores the American premise of 'liberty and justice for all.' This is also evidenced by the focus on equal rights in all aspects of American society and government. Within American organizations, hierarchy is established for convenience, superiors are always accessible and managers rely on individual employees and teams for their expertise. Both managers and employees expect to be consulted and information is shared frequently. At the same time, communication is informal, direct and participative" (Hofstede,
"US Country Profile" www.geert-hofstede.com). From the author's perspective, there tends to be a lot of delegation to employees in US organizations rather than having all power and processes concentrated with top management. Furthermore, cooperation and interactions across the various power levels tend to be quite frequent. Americans are taught from a young age to question, search and analyze. Questioning authority is not seen as a problem but rather as a healthy opportunity for growth and improvement. Americans seek facts and want to understand the why; they de-emphasize the person and instead focus more on the individual's ideas.

With regard to Individualism versus Collectivism (IDV), the US ranks among the nations with the most individualistic scores in the world (91). This dimension refers to how important (or not) social relationships are in a given culture. In nations with low scores, group membership and affiliation is strongly emphasized; in countries with high scores, responsibility and focus is placed on more of an individual basis (Hofstede, "US Country Profile" www. geert-hofstede.com). Individualism is among the most important cultural values for Americans and it is reflected in many facets of life in the USA; in order to comprehend Americans, this should be understood. Independence is actively encouraged from a young age; being free and able 'to make up one's own mind' is idealized. This, however, goes hand-in-hand with then being responsible for one's own actions. For example, in more collectivistic nations credit and blame are often distributed across the group while in the USA it is frequently the case that a single person can be held responsible for the outcome of a project. Americans think of themselves as unique, and 
as responsible for their own destinies. In both the personal and professional arenas, self-reliance and initiative are highly valued; hiring and promotion tend to be merit-based and employees are appreciated for what they can do and actually do.

The Masculinity versus Femininity (MAS) index reflects a society's tendency towards either a focus on assertive and performance related behavior as well as the potential for material reward ('masculine') or a focus on cooperation, quality of life and moderation ('feminine'). The MAS score for the USA is 62 , which indicates that it is more of a masculine society, reflecting the values of competition, achievement, and success; "Behavior in school, work, and play are based on the shared values that people should 'strive to be the best they can be' and that 'the winner takes all'” (Hofstede, "US Country Profile” www.geert-hofstede.com). Personal and professional achievement are expected and admired, thus Americans tend to work hard and are often competitive. Americans are proud of their accomplishments and expect that others are proud of their own as well. That said, there is a fine line between being proud of oneself and being arrogant, and the latter has a negative connotation in the USA. Cultures with a higher need for modesty may also find Americans' focus on achievement self-centered or excessive. Nevertheless, status is often defined by these accomplishments, a situation which differs from many nations where it is more derived by affiliations.

The Uncertainty Avoidance (UAI) index is focused on how comfortable a culture is (or isn't) with ambiguity, e.g. how much risk is acceptable and how does one approach the unknown. High UAI scores indicate a relatively high level of discomfort with uncertainty. Many Americans tend to be quite comfortable with ambiguity and uncertainty and the UAI score (46) reflects this fact. Consequently, there are not a lot of rules; however, when they do exist, they are generally followed and are applied in the same way to everyone. This contrasts with the author's experience in some CEE countries where there may be more rules, but many of them exist 'on paper' only or they are applied indiscriminately. Americans are usually open to new and different ideas, and there is a high level of freedom of expression (also protected under the US Constitution). Change is seen as expected and healthy. The high tolerance for uncertainty can also be seen in the innovative character of American businesses and entrepreneurship. For example, in comparison to managers originating in countries with higher UAI scores, American executives may be prone to taking higher risks; in addition, mid-level managers are often empowered with more autonomy than their international peers.
The Long-Term Orientation (LTO) dimension looks at the importance of time and tradition within a society. High LTO scores are shown by nations with long-term perspectives, where planning is done far in advance, and savings and investment are prioritized. Nations with lower LTO scores tend to focus more on shorter-term goals and place less emphasis on traditions. With an LTO score of 29, the USA has a rather short-term placement. This gives US organizations a certain freedom from long-term commitments in terms of having a relatively high degree of flexibility and ability to react swiftly to new opportunities. Americans and US businesses tend to be quite results oriented; as mentioned above, time is considered a commodity to be efficiently and effectively used. The 'bottom line' is critical. In the professional sphere, the measurement of performance is both routine and valued. This is commonly reflected in human resource policies.

In 2010, another index was added to the dimensions. Indulgence is "a tendency to allow relatively free gratification of basic and natural human desires related to enjoying life and having fun. Its opposite pole, restraint, reflects a conviction that such gratification needs to be curbed or regulated by strict social norms" (Hofstede, Hofstede and Minkov, 2010, p. 281). Together these two items make up the indulgence versus restraint (IVR) continuum. It is important to remember that fulfillment of wants refers to having fun and enjoying life not to satisfying all human desires. In other words, within indulgence, there is a certain perception that one can do as one pleases and indulge oneself in leisure-related activities (high IVR score), while in more restraint oriented nations, behavior is more subject to austere norms and open indulgence is censured (low IVR score). The IVR score of the USA is 68; other English speaking countries generally rank in the high 60s to low 70s, which indicates a fairly permissive society. From the author's viewpoint, American society illustrates a variety of perspectives on this dimension depending on geographical, philosophical, and social backgrounds. However, in general, while Americans are known for working hard and being productive in the professional sphere, they are also known for pampering themselves with things they perceive themselves as deserving. For example, it is typical for Americans to have many of the latest gadgets, and the innovative character of American society fosters this indulgence even further. A great deal of emphasis is placed on 'work / life balance' and participation in free time and extracurricular activities is actively encouraged within the society from childhood.

The graph below provides detailed information on the six cultural dimension identified by Hofstede; data is provided for the United States as well as the eight countries within the Central European area. 
Table 3 Hofstede's Cultural Dimensions - USA \& CEE Countries

\begin{tabular}{|l|c|c|c|c|c|c|}
\hline NATION & PDI & IDV & MAS & UAI & LTO & IVR $^{*}$ \\
\hline USA & 40 & 91 & 62 & 46 & 29 & 68 \\
\hline Austria & 11 & 55 & 79 & 70 & 31 & 63 \\
\hline Czech Rep. & 57 & 58 & 57 & 74 & 13 & 29 \\
\hline Germany & 35 & 67 & 66 & 65 & 31 & 40 \\
\hline Hungary & 46 & 80 & 88 & 82 & 50 & 31 \\
\hline Poland & 68 & 60 & 64 & 93 & 32 & 29 \\
\hline Slovakia & 104 & 52 & 110 & 51 & 38 & 28 \\
\hline Slovenia & 71 & 27 & 19 & 88 & N/A & 48 \\
\hline Switzerland & 34 & 68 & 70 & 58 & 40 & 66 \\
\hline
\end{tabular}

Note: Indulgence versus Restraint (IVR*) data result from a study performed by Michael Minkov in 2010. This dimension is referenced in "Cultures \& Organizations, Software of the Mind", written by Geert Hofstede, Geert Jan Hofstede \& Michael Minkov. Data are ranked on a 100 point scale.

Source: Author's creation based on data from http://geert-hofstede. com; and, IVR data sourced from: http:// www.targetmap.com/viewer. aspx?reportld=6693

\section{Managerial Implications}

Knowing the specifics of a national culture, including some of its key values and underlying assumptions, can help a manager better understand the subtleties affecting the international business situation. This article has overviewed some of the key aspects, dimensions, and dominant values common to Americans and thus US business people. By examining the various cultural similarities and differences between our home country and the nationality of our business partners, we can better facilitate communications and business interactions.

Americans idealize individuality more than almost any other country in the world. This differs from the level of emphasis placed on it in many CEE nations. American culture also illustrates a relatively low acceptance of power differentiation and hierarchy compared to most CEE countries. In addition, Americans have a relatively high level of comfort with ambiguity when examined in the CEE context.
Executives can benefit from looking at the specifics of their home nation and comparing it to the American context as a means of identifying specific potential issues. However, it is also important to remember that these frameworks present a theoretical view and that while many traits are extoled and exhibited by many Americans, it is not possible to universally state these to be true in all cases. Exceptions to every rule exist. To complement the theoretical frameworks mentioned in the article, the author has tried to provide real-life examples gained through extensive personal and professional experience living and working in both environments. This was done in an attempt to shed light on some of the subtleties affecting interactions encountered between American and CEE personnel.

\section{References}

Althen, G., Doran, A. R., Szmania, S. J. (2003). American Ways: A Guide for Foreigners in the United States, $2^{\text {nd }}$ ed. Boston: Intercultural Press.

Lanier, A., Davis, J. (2005). Living in the USA, $6^{\text {th }}$ ed. Boston: Intercultural Press.

Hofstede, G. National Culture Dimensions, "US Country Profile”, (accessed 23 July 2012), [available at http:// geert-hofstede.com/united-states.html].

Hofstede, G., Hofstede, G. J., \& Minkov, M. (2010). Cultures and organizations: software of the mind, $3^{\text {rd }}$ ed. New York: McGraw-Hill.

Target Map, Knowledge Beyond Borders, “Hofstede’s indulgences”, (accessed 23 July 2012), [available at http:// www.targetmap.com/viewer.aspx?reportId=6693].

Author

Gina M. Cook, Ph.D. Assistant Professor University of Economic, Prague Department of International Business Nam. W. Churchilla 4, 13000

Prague 3, Czech Republic cook@vse.cz 